H. Y. BAE, D. HÖFlER, P. S. J. KAIB, P. KASAPLAR, C. K. DE, A. DÖhRING, S. LEE, K. KAUPMEES, I. LEITO, B. LIST* (MAX-PLANCK-INSTITUT FÜR KOHLENFORSCHUNG, MÜLHEIM AN DER RUHR, GERMANY AND UNIVERSITY OF TARTU, ESTONIA)

Approaching Sub-ppm-Level Asymmetric Organocatalysis of a Highly Challenging and Scalable Carbon-Carbon Bond Forming Reaction

Nat. Chem. 2018, 10, 888-894.

\title{
Activating Ketones with Low Catalyst Loadings of a Potent Chiral Lewis Acid
}

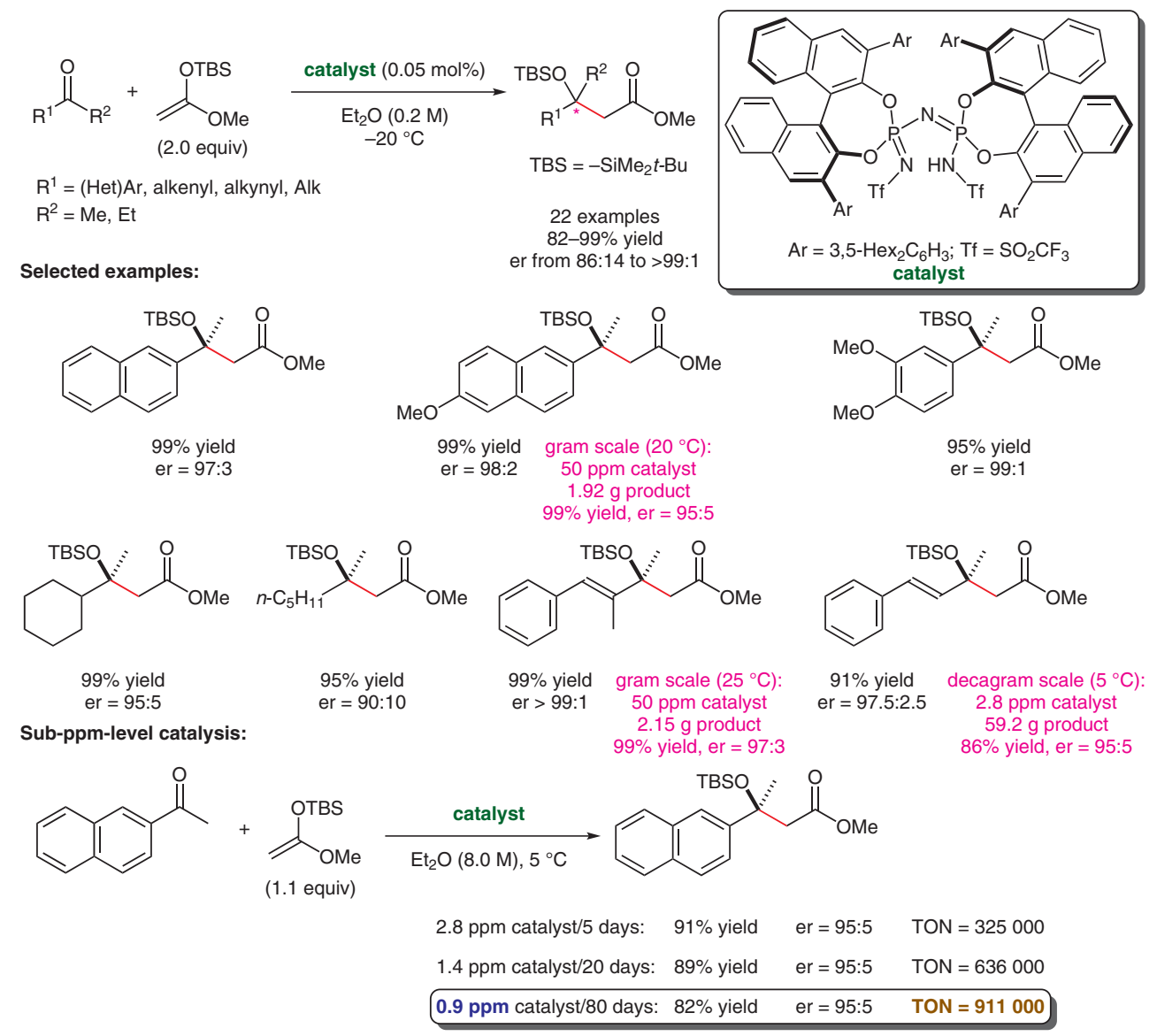

Significance: List and co-workers report the use of chiral organic Lewis acids at ppm- and subppm levels as catalysts for the challenging asymmetric Mukaiyama aldol reaction of ketones with silyl ketene acetals. The corresponding products were obtained in excellent yields and enantioselectivities, even on a decagram scale. The extremely low catalyst loading is unprecedented in catalytic asymmetric $\mathrm{C}-\mathrm{C}$ bond-forming reactions.
Comment: Aldehydes are commonly used as electrophiles in the catalytic asymmetric Mukaiyama aldol reaction, whereas ketones have remained a challenge as substrates for this transformation. The presented work shows the excellent performance of silylated chiral imidodiphosphorimidates (Angew. Chem. Int. Ed. 2016, 55, 13200) as powerful Lewis acid catalysts in the aforementioned reaction of both aryl- and alkyl-substituted ketones.

\section{Key words}

Lewis acid organocatalysis

Mukaiyama aldol reaction

ketones

silyl ketene acetals

C-C bond formation

asymmetric

catalysis

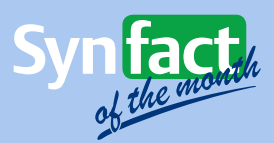

SYNFACTS Contributors: Benjamin List, David Díaz-Oviedo

Synfacts 2018, 14(10), 1089 Published online: 17.09.2018 Dol: 10.1055/s-0037-1610913; Reg-No.: B07418SF 